\title{
Blowing Bubbles Helps Intubation
}

\author{
David Howe \\ Anaesthetic Department, Princess Royal Hospital, Apley, Telford TF1 6TF, UK
}

\section{Abstract}

Rocuronium is commonly used in preference to suxamethonium for rapid sequence induction in the Intensive Care Unit (ICU). We describe a patient who suffered significant neck trauma following a suicide attempt. On initial presentation to accident and emergency, he was an easy intubation with a Grade 1 view obtained at laryngoscopy. After surgery to repair his neck laceration, he was extubated and discharged from ICU. He later developed a severe aspiration pneumonia and required reintubation. After induction and paralysis with suxamethonium, the best view at laryngoscopy was a Grade 3 despite the use of different laryngoscopes. As the muscle paralysis wore off the patient began breathing. This produced bubbles in the back of the patient's pharynx which directed the clinician to the laryngeal inlet to allow successful intubation. In this case, the short duration of action of suxamethonium significantly aided intubation due to the return of spontaneous breathing by the patient.

Keywords: Difficult airway, rapid sequence induction, suxamethonium

\section{INTRODUCTION}

In recent years, there has been a move in intensive care toward using rocuronium over suxamethonium for rapid sequence induction (RSI) in the Intensive Care Unit (ICU). This is because of perceived superior intubating conditions obtained and because rocuronium has a better side effect profile. It is however associated with a relatively high incidence of anaphylaxis and has a longer duration of action, but is reversible with the use of sugammadex. Suxamethonium has the advantage of having a very rapid onset and short duration of action. It is associated with several side effects including transient hyperkalemia, myalgia, arrhythmias, anaphylaxis, suxamethonium apnea, and malignant hyperpyrexia. However, this case outlines how the short duration of action of suxamethonium can assist intubation in difficult airways because as the patient starts to self-ventilate, the production of bubbles in respiratory secretions can help locate the laryngeal inlet.

\section{Case Report}

We describe a 56-year-old man who had attempted suicide by tying a ligature around his neck with the other end tied to a post. He then drove off at high acceleration in his car. His height was $175 \mathrm{~cm}$ and he weighed $75 \mathrm{~kg}$. He was brought into accident and emergency (A\&E) conscious and alert but with significant trauma to the front of his neck and excessive

\begin{tabular}{|l|l|}
\hline \multicolumn{3}{|c|}{ Access this article online } \\
\hline Quick Response Code: & Website: \\
& www.ijccm.org \\
& \\
&
\end{tabular}

bleeding into his airway. He was intubated in A\&E and was a Grade 1 intubation. He was then taken to theatre for debridement and closure of his wound. He was extubated within $48 \mathrm{~h}$ and then discharged to the surgical ward with a nasogastric tube in situ for feeding. On day 10 of his admission while he was on the ward, he developed an aspiration pneumonia and deteriorated. He was readmitted to ITU and required immediate reintubation.

He was induced with $150 \mathrm{mg}(2 \mathrm{mg} / \mathrm{kg})$ propofol and paralyzed with $100 \mathrm{mg}(1.3 \mathrm{mg} / \mathrm{kg})$ suxamethonium. At laryngoscopy, only a Grade 3 view could be obtained with a size 4 Macintosh blade. Despite several attempts to improve the view with different laryngoscopes and attempts to pass a bougie blindly, it was not possible to intubate the patient. Saturations were maintained by bag-mask ventilation of the patient which was easy. The patient's anatomy was significantly distorted due to the trauma and swelling of recent surgery. Eventually, the paralysis wore off and the patient began self-ventilating. This produced bubbles in secretions that allowed the practitioner to direct the endotracheal tube toward the glottis and intubate the patient.

Address for correspondence: Dr. David Howe, Anaesthetic Department, Princess Royal Hospital, Apley, Telford TF1 6TF, UK. E-mail: davidhowe337@gmail.com

This is an open access article distributed under the terms of the Creative Commons Attribution-NonCommercial-ShareAlike 3.0 License, which allows others to remix, tweak, and build upon the work non-commercially, as long as the author is credited and the new creations are licensed under the identical terms.

For reprints contact: reprints@medknow.com

How to cite this article: Howe D. Blowing Bubbles Helps Intubation. Indian J Crit Care Med 2017;21:710-1. 


\section{Discussion}

There has been a general move away from using suxamethonium in favour of using rocuronium for RSI in the ICU. This is despite a Cochrane review which favoured the intubating conditions achieved with suxamethonium. ${ }^{[1]}$ This study did not take into consideration the additional benefit that the production of bubbles around the patient's glottis can provide in helping guide intubation in difficult patients, once the paralysis wears off and the patient starts self-ventilating. Although such cases of difficult intubation are thankfully uncommon, when faced with an unanticipated difficult airway, any minor factor which can improve the chance of success can have a significant effect on the outcome of the patient.

\section{Conclusion}

In this case, the use of suxamethonium with its short duration of action undoubtedly helped guide intubation due to the production of bubbles in secretions around the glottis.

\section{Declaration of patient consent}

The authors certify that they have obtained all appropriate patient consent forms. In the form the patient(s) has/have given his/her/their consent for his/her/their images and other clinical information to be reported in the journal. The patients understand that their names and initials will not be published and due efforts will be made to conceal their identity, but anonymity cannot be guaranteed.

\section{Financial support and sponsorship}

Nil.

\section{Conflicts of interest}

There are no conflicts of interest.

\section{Reference}

1. Tran DT, Newton EK, Mount VA, Lee JS, Wells GA, Perry JJ. Rocuronium versus succinylcholine for rapid sequence induction intubation. Cochrane Database Syst Rev 2015;(1):CD002788. 